\title{
Dyslipidemia in Chronic Kidney Disease: Contemporary Concepts and Future Therapeutic Perspectives
}

\author{
Panagiotis Theofilis Aikaterini Vordoni Maria Koukoulaki \\ Georgios Vlachopanos Rigas G. Kalaitzidis \\ Department of Nephrology, General Hospital of Nikaia-Piraeus, Athens, Greece
}

\author{
Keywords \\ Dyslipidemia - Chronic kidney disease - Gut microbiota . \\ Proprotein convertase subtilisin/kexin type 9 . \\ Hypertriglyceridemia
}

\begin{abstract}
Background: Chronic kidney disease (CKD) is an increasingly prevalent disease state met with great morbidity and mortality primarily resulting from the high incidence of adverse cardiovascular outcomes. Therapeutic strategies in this patient population aim at controlling modifiable cardiovascular risk factors, including dyslipidemia. Summary: In this review article, we first provide the latest pathophysiologic evidence regarding the altered dyslipidemia pattern in CKD, followed by its contemporary management according to the latest guidelines. Moreover, we present the current progress regarding the emerging therapeutic strategies. Key Messages: The presence of renal impairment leads to alterations in cholesterol structure, metabolism, and reverse transport paired with increased oxidative stress. Statins remain the cornerstone of dyslipidemia management in patients with kidney dysfunction who are at risk for cardiovascular events. However, their efficacy is debatable in end-stage renal dis-
\end{abstract}

ease under renal replacement therapy. Therefore, novel treatment approaches aiming at hypertriglyceridemia, proprotein convertase subtilisin/kexin type 9 , and lipoprotein(a) are under rigorous investigation while the research of gut microbiome might provide additional mechanistic and therapeutic insight.

(c) 2021 S. Karger AG, Basel

\section{Introduction}

Chronic kidney disease (CKD) represents an entity with increasing incidence over the past decades due to the rising prevalence of the most frequent etiologic factors of renal disease, that is, diabetes mellitus (DM) and arterial hypertension. For DM specifically, the incidence of endstage diabetic nephropathy was higher by approximately $10 \%$ in the span of 15 years (2000-2015) [1].

With regard to cardiovascular diseases, the presence of kidney disease is believed to be a major independent risk factor. A recent analysis suggested that $7.6 \%$ of yearly deaths from cardiovascular diseases were related to renal dysfunction [2]. Other than the impact on atherosclerosis, progression of CKD was found to be related to myo- 


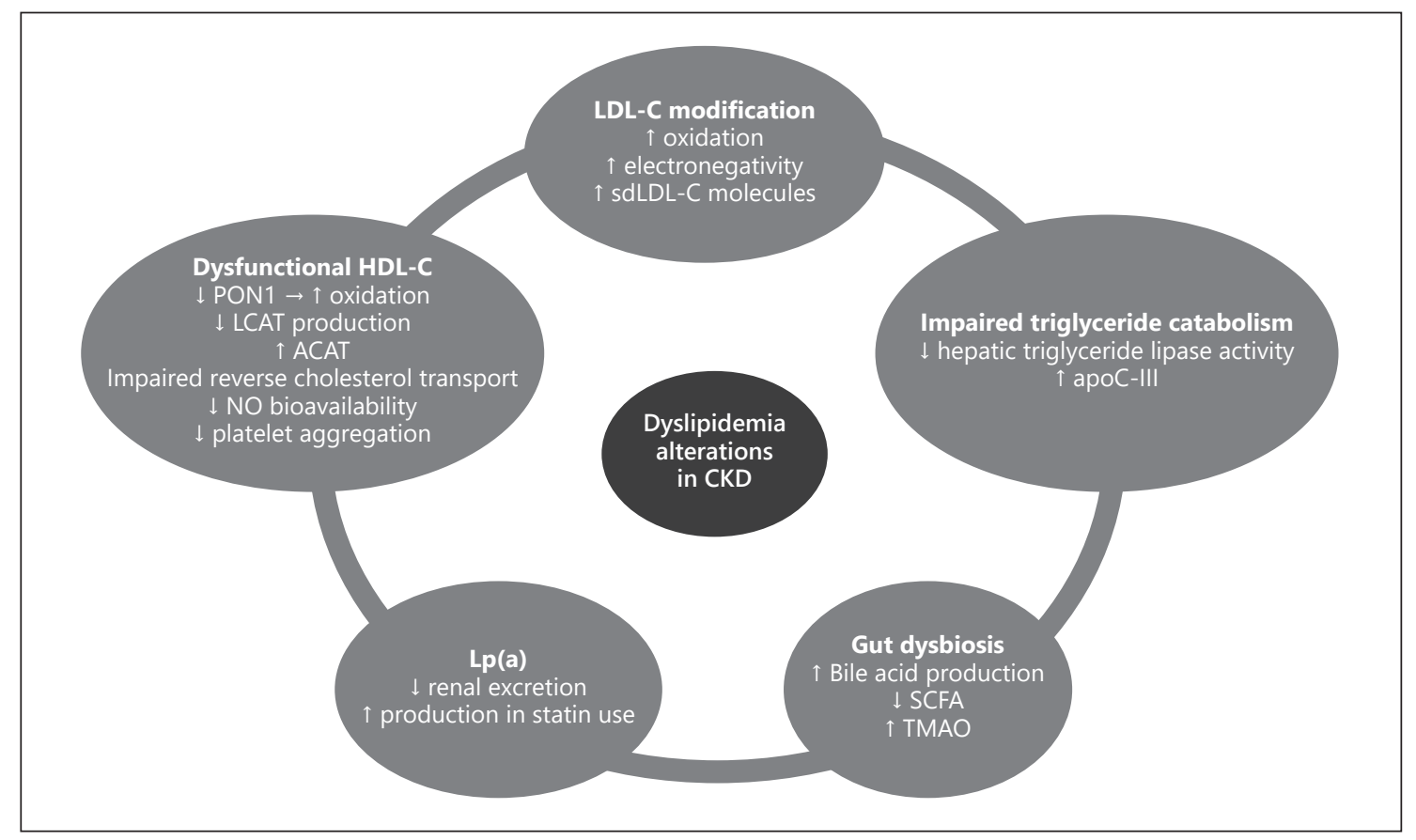

Fig. 1. Chronic kidney disease-induced alterations in the dyslipidemia profile induced by LDL-C modifications, reduced HDL-C functionality, impaired triglyceride catabolism, Lp(a), and gut dysbiosis. LDL-C, low-density lipoprotein cholesterol; HDL-C, high-density lipoprotein cholesterol; sdLDL-C, small dense LDL-C; apoC-III, apolipoprotein C-III; SCFA, short-chain fatty acids; TMAO, trimethylamine N-oxide; PON-1, paraoxonase 1; LCAT, lecithin-cholesterol acyltransferase; ACAT, acetyl-coenzyme A acetyltransferase; NO, nitric oxide.

cardial fibrosis independently from left ventricular afterload, a finding which may account for the increased incidence of the cardiorenal syndrome and ultimately mortality [3]. Atrial fibrillation is another clinically relevant entity frequently seen in CKD patients, accounting for increased risk of embolic stroke and death despite the available oral anticoagulation strategies [4]. It should also be noted that sudden cardiac death rates are high especially in dialysis-dependent CKD, more commonly resulting from fatal bradyarrhythmias partly deriving from electrolyte imbalances [5].

In light of this evidence, strategies limiting residual cardiovascular risk in this patient population are focused on the intense treatment of the conventional modifiable risk factors as well as kidney disease-specific parameters [6]. With regard to dyslipidemia, important alterations in the lipid profile of patients with CKD are present, with predominant hypertriglyceridemia as well as changes in lipoprotein structure and functions. Controversy also exists on the optimal management of dyslipidemia for cardiovascular disease prevention in CKD patients while evidence suggests that lipids are implicated in the progression of CKD. Therefore, this review deals with the latest research concerning dyslipidemia in the CKD population as well as provides insight on the novel treatment approaches from recent studies.

\section{Mechanistic Insight into Dyslipidemia Patterns of CKD}

\section{$C K D$ and $L D L-C$}

Even though low-density lipoprotein cholesterol (LDLC) levels correlate significantly with cardiovascular risk in the general population, the composition and structure are more important predictors of adverse outcomes in the case of CKD (shown in Fig. 1). First and foremost, oxidation of LDL-C on the basis of inflammation and increased oxidative stress in the context of CKD may account for its greater atherogenic potential despite lower levels [7]. Moreover, higher levels of electronegative LDL-C due to the increase of its L5 subfraction in CKD could result in increased inflammatory burden and, therefore, accelerated atherosclerosis as it enhances the differentiation of monocytes to pro-inflammatory M1 macrophages via action on the lectin-like oxidized LDL receptor- 1 as well as NLRP3 inflammasome activation $[8,9]$. Moving on, small 
dense LDL-C particles merit specific attention due to their easier oxidation and ability to penetrate the arterial wall [10]. A recent meta-analysis displayed a relationship between these molecules and coronary artery disease [11] while their levels could be indicative of future cardiovascular events in CKD $[12,13]$.

\section{The Role of HDL-C}

High-density lipoprotein cholesterol (HDL-C) is a molecule known for its cardioprotective effect. Under physiologic conditions, HDL is an important mediator of endothelial function since it activates endothelial nitric oxide synthase leading to an increase in NO levels while also counteracting the production of reactive oxygen species $[14,15]$. Furthermore, it is believed to possess antiinflammatory and antithrombotic properties $[16,17]$. In the setting of $\mathrm{CKD}$, the beneficial actions of HDL-C are largely lost. To begin with, paraoxonase 1 appears to be an important determinant since its low levels have been linked with enhanced HDL oxidation, while in its absence, the concentration of malondialdehydes may accentuate phosphorylation of endothelial nitric oxide synthase and thus constrain NO availability $[18,19]$. Other mechanisms have also been suggested, such as the reduced ApoA-1 and lecithin-cholesteryl acyltransferase production, the upregulation of acetyl-CoA acetyltransferase-1, the oxidation of HDL constituents, and the impaired reverse cholesterol transport [20]. Ultimately, the resulting endothelial dysfunction, inflammation, and oxidative stress could be responsible for the association between HDL and increased mortality in CKD [21]. Another interesting concept was presented by Florens et al. [22] who showed that CKD-induced carbonylation of HDL was responsible for impaired platelet aggregation, further contributing to the etiology of increased cardiovascular events in the CKD population.

\section{Hypertriglyceridemia in CKD}

Elevated serum triglycerides represent the most frequent abnormality in the lipid profile of CKD patients. The main mechanism involved is their hindered catabolism due to the hypoactive hepatic triglyceride lipase. In addition, an increased amount of lipase inhibitors, namely, apoC-III, in the setting of uremia may also play a role in decreased lipoprotein lipase-dependent triglyceriderich lipoprotein catabolism [23]. Importantly, triglyceride-rich lipoproteins were recently proven to be important risk factors for cardiovascular outcomes in CKD patients, highlighting a potential novel therapeutic target [24].

The Impact of Dyslipidemia in Chronic Kidney Disease

\section{Lipoprotein (a)}

The effect of $\operatorname{Lp}(\mathrm{a})$ on inflammation, atherosclerosis, and thrombosis has been well established in the past years, with the formation of a definite bond between its levels and adverse cardiovascular events [25-27]. Concerning its structure, it consists of Apo-B linked with apolipoprotein(a), encrypted by the LPA gene whose expression is primarily mediated by the liver and secondarily by the kidneys [27]. Furthermore, Lp(a) clearance mainly depends on kidney function, thus resulting in higher levels as glomerular filtration rate deteriorates, especially in those with large apolipoprotein(a) isoforms $[28,29]$. It was recently suggested that elevated $\operatorname{Lp}(a)$ was an independent risk factor for the incidence of myocardial infarction and death in CKD patients [26]. Interestingly, statin prescription in high-risk populations could account for the increased $\operatorname{Lp}(\mathrm{a})$ concentration with potential mechanisms involving higher LPA mRNA expression and proprotein convertase subtilisin/kexin type 9 (PCSK9) levels following statin use [30].

\section{Gut Microbiota and Lipid Metabolism}

In CKD patients, a dysbiotic intestinal environment has been noted in a recent study [31]. With regard to dyslipidemia, several intestinal bacteria were shown to be able to produce bile acids from the intestinal bile salt pool leading to hepatic and systemic lipid adjustments via action on the nuclear or G protein-coupled receptors [32]. Moreover, lack of specific bacteria involved in the fermentation of nondigestible carbohydrates could result in loss of beneficial metabolites, namely, short-chain fatty acids, which are significant regulators of lipid metabolism [33]. Trimethylamine $\mathrm{N}$-oxide (TMAO), a product of gut microbiome-related metabolism of choline and L-carnitine, has also been associated with pro-atherosclerotic effects via modulation of reverse cholesterol transport, cholesterol metabolism, and bile acid composition [34-36].

\section{Treatment of Dyslipidemia in CKD}

\section{Dietary Considerations}

Essential dietary modifications are the initial step toward the management of dyslipidemia in CKD. Mediterranean diet has been extensively studied, providing evidence of ameliorated lipid profiles in CKD patients as well as post-kidney transplantation [37, 38]. Moreover, the benefits of a low-protein diet on cholesterol levels and kidney function were recently reported in patients with advanced CKD [39]. A high-fiber diet was also met with

Am J Nephrol 2021;52:693-701 
Table 1. International guideline recommendations toward LDL cholesterol-lowering therapy in patients with CKD

\begin{tabular}{|c|c|c|c|}
\hline & $\mathrm{ACC} / \mathrm{AHA}[42]$ & ESC/EAS [43] & $\operatorname{CCS}[44]$ \\
\hline Publication year & 2018 & 2019 & 2016 \\
\hline \multicolumn{4}{|l|}{ Nondialysis-dependent CKD } \\
\hline Indications & $\begin{array}{l}\text { Age } 40-75 \text { years + LDL-C between } 70 \text { and } \\
189 \mathrm{mg} / \mathrm{dL}+10 \text {-year ASCVD risk } \geq 7.5 \%\end{array}$ & KDOQI stage 3-5 CKD & $\begin{array}{l}\text { Age } \geq 50 \text { years }+ \text { eGFR }<60 \mathrm{~mL} / \\
\mathrm{min} / 1.73 \mathrm{~m}^{2} \text { or } A C R>3 \mathrm{mg} / \mathrm{mmol}\end{array}$ \\
\hline Treatment & Moderate intensity statin \pm ezetimibe $(\mathrm{I}-\mathrm{A})$ & Statin \pm ezetimibe $(\mathrm{I}-\mathrm{A})$ & Statin \pm ezetimibe (strong-high) \\
\hline \multicolumn{4}{|l|}{ Dialysis-dependent CKD } \\
\hline On LDL-lowering therapy & Continuation of statin (Ilb-C) & Continuation of therapy (Ila-C) & $\begin{array}{l}\text { Continuation of therapy (conditional- } \\
\text { low) }\end{array}$ \\
\hline Treatment naïve & Statin initiation not recommended (III-B) & $\begin{array}{l}\text { Statin initiation not recommended } \\
\text { if free from ASCVD (III-A) }\end{array}$ & $\begin{array}{l}\text { Statin initiation not recommended } \\
\text { (conditional-moderate) }\end{array}$ \\
\hline Kidney transplantation & No recommendation & Statin (Ila) \pm ezetimibe (Ilb) & Statin (conditional-moderate) \\
\hline
\end{tabular}

Information in brackets corresponds to strength of recommendation-level of evidence. ASCVD, atherosclerotic cardiovascular disease.

favorable outcomes in the means of improved quality of life and lipid profile within 6 weeks of initiation [40]. Recently, resveratrol supplementation was shown to dosedependently improve kidney function and lipid metabolism via autophagy modulation in an experimental model of diabetic nephropathy [41].

\section{Statins-Ezetimibe}

Statin therapy has been the main focus of published international guidelines through the years (Table 1), and CKD frequently consists of an indication for statin prescription. The most recent international guidelines on the management of dyslipidemias recommend treatment with a statin up until stage $5 \mathrm{CKD}$ [42-44], despite the limited benefit observed in this subgroup of patients.

The major clinical trials demonstrated important reductions in adverse cardiovascular outcomes following statin therapy in nondialysis-dependent CKD [45, 46]. However, the effect appears to be variable, mainly depending on the degree of kidney dysfunction (shown in Fig. 2). Even though meta-analytic data display significant reductions in cardiovascular outcomes of patients with $\mathrm{CKD}$, they have also stressed the declining benefit of statin treatment with worsening renal function [47-49]. Regarding a possible effect of statin therapy on CKD progression, this has not been proven since they did not result in slower CKD progression despite reduction of proteinuria according to the published meta-analyses $[48,50]$. Last but not least, statins appear to be beneficial in subjects with autosomal dominant polycystic kidney disease if started early in the disease course, owing to their pleiotropic mechanism of action [51]. As far as the side effects of statin therapy are concerned, no significant differences have been noted compared to placebo in major trials [52].

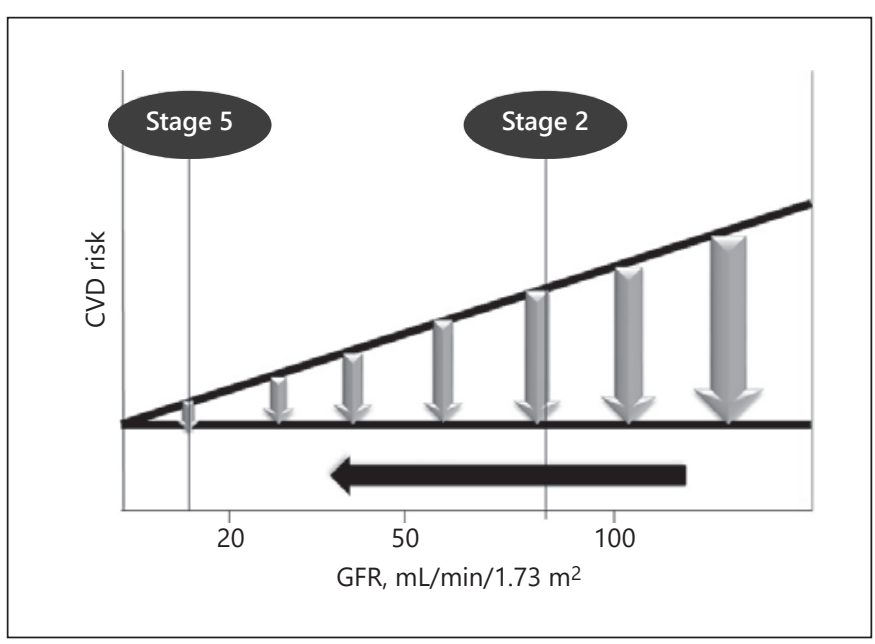

Fig. 2. Schematic representation of the declining benefit of statins in cardiovascular risk reduction with worsening renal function.

Ezetimibe, acting on the small intestine to inhibit cholesterol absorption thus increasing circulating cholesterol uptake by hepatocytes, is an important add-on treatment in CKD patients also. In a recently reported meta-analysis, the combination of ezetimibe with statins led to a greater reduction of all-cause mortality and adverse cardiovascular outcomes paired with improvement in cholesterol and triglyceride levels compared to statin monotherapy [49].

As far as patients on dialysis are concerned, inconsistent benefit has been reported following statin treatment. Even though the current guidelines recommend against the initiation of statins in patients on dialysis owing to the negative results of the 4D and AURORA trials [43], it appears that some subgroups are met with significant ben- 
Table 2. Potential therapeutic approaches against dyslipidemia in the setting of CKD

\begin{tabular}{|c|c|c|c|}
\hline Study & Agent & CKD population & Outcome \\
\hline \multicolumn{4}{|l|}{ PPAR agonism } \\
\hline Yokote et al. [61] & Pemafibrate (PPARa agonist) & $\begin{array}{l}\text { All eGFR ranges } \\
\text { Dialysis patients not included }\end{array}$ & Correction of lipid abnormalities in CKD patients \\
\hline Lin et al. [62] & Pioglitazone (PPARy agonist) & Diabetics with ESRD & $\begin{array}{l}\downarrow \text { MACCE-related death in the pioglitazone group with } \\
\text { dyslipidemia compared with DPP4 inhibitors users }\end{array}$ \\
\hline Yen et al. [63] & Pioglitazone (PPARy agonist) & Diabetics with advanced CKD & $\downarrow$ MACCE and all-cause mortality in the pioglitazone arm \\
\hline Charytan et al. [64] & Evolocumab & $\mathrm{eGFR} \geq 30 \mathrm{~mL} / \mathrm{min} / 1.73 \mathrm{~m}^{2}$ & $\begin{array}{l}\text { Lipid-lowering and clinical efficacy maintained in CKD } \\
\uparrow \text { cardiovascular events reduction with worsening renal function }\end{array}$ \\
\hline Lee et al. [65] & Evolocumab & All eGFR ranges + hemodialysis & $\begin{array}{l}\text { Similar LDL-C reduction in severe renal dysfunction and } \\
\text { hemodialysis }\end{array}$ \\
\hline Tuñón et al. [66] & Alirocumab & $\mathrm{eGFR}>30 \mathrm{~mL} / \mathrm{min} / 1.73 \mathrm{~m}^{2}$ & $\begin{array}{l}\downarrow \text { adverse cardiovascular outcomes across the different groups } \\
\text { according to renal function }\end{array}$ \\
\hline Wright et al. [67] & Inclisiran & $\mathrm{CrCl} \geq 15 \mathrm{~mL} / \mathrm{min}$ & $\begin{array}{l}\text { Similar pharmacodynamics and pharmacokinetic effect in } \\
\text { normal and impaired kidney function }\end{array}$ \\
\hline \multicolumn{4}{|l|}{ Lp(a) inhibition } \\
\hline \multicolumn{4}{|c|}{ Gut microbiota modulation } \\
\hline Han et al. [69] & Chickpea dietary fiber & & $\begin{array}{l}\uparrow \text { Bacteroides and Lactobacillus species } \\
\text { Correction of lipid profile }\end{array}$ \\
\hline Wang et al. [70] & Green tea leaf powder fiber & & $\begin{array}{l}\uparrow \text { Blautia, Oscillibacter, Ruminiclostridium, Alloprevotella, and } \\
\text { Butyrivibrio species } \\
\downarrow \text { Erysipelatoclostridium, Desulfovibrio, and Candidatus } \\
\text { saccharimonas species } \\
\text { Prevention of high-fat diet-induced dyslipidemia }\end{array}$ \\
\hline Zhang et al. [71] & $\begin{array}{l}\text { lodomethylcholine (TMAO } \\
\text { inhibitor) }\end{array}$ & CKD model of apoE $E^{-/-}$mice & $\begin{array}{l}\text { Favorable cardiovascular outcomes } \\
\downarrow \text { plasma cholesterol levels }\end{array}$ \\
\hline
\end{tabular}

PPAR, peroxisome proliferator-activated receptor; MACCE, major adverse cardiac and cerebrovascular event; DPP4, dipeptidyl peptidase-4; TMAO, trimethylamine $\mathrm{N}$-oxide. $\uparrow$ indicates an increase; $\downarrow$ indicates a decrease.

efits, such as dialysis patients with atherosclerotic cardiovascular disease or significant hypercholesterolemia [53]. Continuing long-term statin therapy after dialysis initiation is another topic of interest, with the recent study of Streja et al. [54] reporting favorable outcomes in the continuation group.

Regarding patients on peritoneal dialysis, even though statins can potently and effectively lower cholesterol levels [55], only a small proportion of SHARP trial participants were in this dialysis method and did not gain any cardiovascular benefit [56]. Data from a retrospective cohort study using propensity score matching in peritoneal dialysis patients demonstrated reduced all-cause mortality in statin-treated arms [57].

\section{Triglyceride-Lowering Therapy}

Increased triglycerides have been linked with cardiovascular morbidity and mortality, making fibrates a presumably important agent in patients with $\mathrm{CKD}$, characterized by hypertriglyceridemia. Their mechanism of action involves stimulation of peroxisome proliferator-activated receptor alpha (PPARa) which is associated with triglyceride homeostasis while possessing anti-inflammatory and antithrombotic properties.

A meta-analysis conducted in 2012 reported a lower risk of cardiovascular events and mortality in fibrate users with mild-to-moderate CKD [58]. In a recently reported cohort study of patients with advanced CKD, a cardiovascular risk reduction was reported in the fenofibrate treatment arm while also protecting against incident renal function worsening [59]. Potential nephroprotective mechanisms involve attenuated oxidative stress, inflammation, and apoptosis [60]. Pemafibrate has been in the spotlight due to its ability to selectively, potently, and safely interact with PPAR $\alpha$ compared to other fibrates (Table 2). Experimental evidence has shown beneficial lipid alterations and attenuated inflammatory response, collectively halting atherosclerosis progression [72, 73]. 
Moreover, it provides renal protection via reduction of oxidative stress and lipid deposition [74], undergoes primarily hepatic excretion, and has no significant interaction with statins. Pemafibrate demonstrated a significant triglyceride-lowering effect with a good safety profile in $\mathrm{CKD}$ and hemodialysis patients. Another point that merits special notice is the higher drop of triglyceride-rich lipoproteins and small dense LDL-C in those with the most impaired renal function [61].

PPAR $\gamma$ agonists are another important drug category with beneficial effects on dyslipidemia and adverse outcomes. Specifically, treatment with pioglitazone has been associated with a lower incidence of hard endpoints in individuals with DM and advanced CKD $[62,63]$. It should also be noted that recent trials have unveiled novel antifibrotic mechanisms of pioglitazone which could affect the progression of CKD [75].

Regarding $\omega 3$-polyunsaturated fatty acids, eicosapentaenoic acid (EPA) exerts unique cardioprotective properties, namely, via the interactions in membranes and lipoproteins, oxylipin production, free fatty acid receptor-4 signaling, and stimulation of PPAR [76]. Two recently completed trials demonstrated significant benefits of high-dose EPA on adverse cardiovascular events and atherosclerosis in high-risk patients with hypertriglyceridemia under statin therapy [77, 78]. Importantly, the REDUCE-IT trial recruited patients with CKD in whom the benefits remained unaffected. However, the STRENGTH trial reported contradictory findings, making the use of these agents uncertain with regard to cardiovascular benefits, since guideline recommendations were reported before this study [79]. Interestingly, EPA is also implicated in the prevention of palmitate-induced lipotoxicity and subsequent renal proximal tubule injury while also protects against renal fibrosis, thus halting CKD evolution [80, 81].

\section{PCSK9 Inhibitors}

Involved in the degradation of the LDL receptor, PCSK9 inhibition has revolutionized the treatment of dyslipidemia. The randomized controlled trials provided robust evidence on their potency in reducing adverse cardiovascular events [82], being also efficacious in participants with mild-to-moderate renal dysfunction (Table 2) [64, 66]. Unfortunately, none of those trials enrolled patients with severe or dialysis-dependent CKD which creates inevitable gaps in evidence. However, a recent study evaluating evolocumab's pharmacologic properties demonstrated no significant differences in its exposure while maintaining the LDL-lowering properties across severe kidney impairment
(eGFR $15-29 \mathrm{~mL} / \mathrm{min} / 1.73 \mathrm{~m}^{2}$ ) and dialysis-dependent CKD [65]. An analysis of inclisiran studies including patients with CKD (eGFR $\left.\geq 30 \mathrm{~mL} / \mathrm{min} / 1.73 \mathrm{~m}^{2}\right)$ was also performed, reporting similar efficacy and safety to patients with normal kidney function [67].

\section{Emerging Therapeutic Strategies}

$\mathrm{Lp}(\mathrm{a})$ Lowering

$\mathrm{Lp}(\mathrm{a})$ is another risk factor causally and genetically implicated in cardiovascular diseases. Recent PCSK9 studies have shown modest $\mathrm{Lp}(\mathrm{a})$ reductions which are, however, inadequate in providing a meaningful cardiovascular benefit [83]. A novel therapeutic approach has been established in the form of an antisense oligonucleotide targeting the LPA gene mRNA, named pelacarsen. A dosedependent effect was noted in the phase II trial of patients with elevated $\operatorname{Lp}(\mathrm{a})$ and established cardiovascular disease, without significant adverse effects being observed (Table 2) [68]. Unfortunately, patients with advanced CKD were not included in this study and will not be adequately represented in the landmark HORIZON trial currently underway (NCT03506854), making pelacarsen's use in CKD patients questionable.

\section{Gut Microbiome Interventions}

Gut dysbiosis has been linked with alterations in lipid metabolism and, consequently, in accelerated atherosclerosis. Since changes in the intestinal bacterial environment are frequently present in CKD patients and amplify the abovementioned processes, effective modification of the gut microbiome could emerge as a potential therapeutic approach (Table 2). Depletion of bacteria responsible for short-chain fatty acid production due to fermentation of fiber in the setting of kidney impairment has been a target of fiber-rich dietary interventions. Inhibition of TMAO with iodomethylcholine has also resulted in favorable renal and cardiovascular outcomes in hyperlipidemic mice paired with significant reductions in plasma cholesterol levels [71]. Plant-based diets are another promising way of lowering TMAO levels which deserves confirmation in large-scale trials [84].

\section{Dyslipidemia in Renal Transplant Recipients}

The presence of dyslipidemia is common after renal transplantation owing to the mechanism of action of immunosuppressive agents (shown in online suppl. Fig. 1; see www.karger.com/doi/10.1159/000518456) [85]. Statin therapy with caution on potential drug-drug interactions due to metabolism in CYP3A4 is indicated, while the addition of ezetimibe is reasonable in cases of intoler- 
ance or insufficient response [43]. Interestingly, pretransplantation high-intensity statin treatment was met with a survival benefit after transplantation [86].

\section{Nephrotic Syndrome-Related Dyslipidemia}

Uncontrolled and prolonged dyslipidemia in the setting of nephrotic syndrome is an important determinant of CKD due to podocyte injury and mesangial cell proliferation as well as cardiovascular disease development. Increased cholesterol levels in patients with nephrotic syndrome result from multiple mechanisms including the diminished lipoprotein lipase and hepatic lipase activity and the increased PCSK9 levels [87]. Pharmacologic management is largely dependent on statin treatment even though data are limited and inconclusive. LDL apheresis, PCSK9 inhibition, and hepatic angiopoietinlike protein 3 inhibition via RNA interference are alternative approaches that deserve further investigation before adoption in clinical practice.

\section{Conclusion}

Dyslipidemia is a frequent comorbidity in CKD with significant alterations regarding cholesterol structure and metabolism compared to the general population. Statin therapy has been the main focus of published international guidelines through the years up until stage $5 \mathrm{CKD}$, despite the inconsistent effect in this subgroup of patients. With regard to dialysis patients, there is a wide agreement on the continuation of statins at incident dialysis while their initiation is not advised by the current guidelines. However, as demonstrated above, the altered lipid profile in the context of CKD needs to be addressed more thoroughly in future research along with guideline updates with the potential contribution of novel agents targeting PCSK9, Lp(a), PPAR, and the gut microbiome among others.

\section{Conflict of Interest Statement}

The authors declare that they have no known competing financial interests or personal relationships that could have appeared to influence the work reported in this study.

\section{Funding Sources}

None.

\section{Author Contributions}

P.T. contributed to the design, drafted the work, and gave the final approval of the version to be published. A.V. contributed to the design, drafted the work, and gave the final approval of the version to be published. M.K. contributed to the conception, revised the work critically, and gave the final approval of the version to be published. G.V. contributed to the conception, revised the work critically, and gave the final approval of the version to be published. R.G.K. contributed to the conception, revised the work critically, and gave the final approval of the version to be published.

\section{References}

1 Cheng HT, Xu X, Lim PS, Hung KY. Worldwide epidemiology of diabetes-related endstage renal disease, 2000-2015. Diabetes Care. 2021 Jan;44(1):89-97.

2 GBD Chronic Kidney Disease Collaboration. Global, regional, and national burden of chronic kidney disease, 1990-2017: a systematic analysis for the Global Burden of Disease Study 2017. Lancet. 2020 Feb 29;395(10225):709-33.

3 Hayer MK, Radhakrishnan A, Price AM, Liu B, Baig S, Weston CJ, et al. Defining myocardial abnormalities across the swtages of chronic kidney disease: a Cardiac Magnetic Resonance Imaging Study. JACC Cardiovasc Imaging. 2020Nov;13(11):2357-67.

4 Chantrarat T, Krittayaphong R. Oral anticoagulation and cardiovascular outcomes in patients with atrial fibrillation and chronic kidney disease in Asian Population, Data from the COOL-AF Thailand registry. Int J Cardiol. 2021 Jan 15;323:90-9.
5 Genovesi S, Boriani G, Covic A, Vernooij RWM, Combe C, Burlacu A, et al. Sudden cardiac death in dialysis patients: different causes and management strategies. Nephrol Dial Transplant. 2021 Feb 20;36(3):396-405.

6 Mark PB. Strategies to manage cardiovascular risk in chronic kidney disease. Nephrol Dial Transplant. 2018 Jan 1;33(1):23-5.

7 Steinberg D, Witztum JL. Oxidized low-density lipoprotein and atherosclerosis. Arterioscler Thromb Vasc Biol. 2010 Dec;30(12):2311-6.

8 Chang SF, Chang PY, Chou YC, Lu SC. Electronegative LDL induces $\mathrm{M} 1$ polarization of human macrophages through a LOX-1-dependent pathway. Inflammation. 2020 Aug; 43(4):1524-35.

9 Yang TC, Chang PY, Lu SC. L5-LDL from STelevation myocardial infarction patients induces IL- $1 \beta$ production via LOX-1 and NLRP3 inflammasome activation in macrophages. Am J Physiol Heart Circ Physiol. 2017 Feb 1;312(2):H265-74.
10 Anber V, Griffin BA, McConnell M, Packard CJ, Shepherd J. Influence of plasma lipid and LDL-subfraction profile on the interaction between low density lipoprotein with human arterial wall proteoglycans. Atherosclerosis. 1996 Aug 2;124(2):261-71.

11 Liou L, Kaptoge S. Association of small, dense LDL-cholesterol concentration and lipoprotein particle characteristics with coronary heart disease: a systematic review and meta-analysis. PLoS One. 2020;15(11): e0241993.

12 Chu M, Wang AY, Chan IH, Chui SH, Lam CW. Serum small-dense LDL abnormalities in chronic renal disease patients. Br J Biomed Sci. 2012;69(3):99-102.

13 Shen H, Xu Y, Lu J, Ma C, Zhou Y, Li Q, et al. Small dense low-density lipoprotein cholesterol was associated with future cardiovascular events in chronic kidney disease patients. BMC Nephrol. 2016Oct 6;17(1):143. 
14 Mineo C, Yuhanna IS, Quon MJ, Shaul PW. High density lipoprotein-induced endothelial nitric-oxide synthase activation is mediated by Akt and MAP kinases. J Biol Chem. 2003 Mar 14;278(11):9142-9.

15 Brites F, Martin M, Guillas I, Kontush A. Antioxidative activity of high-density lipoprotein (HDL): Mechanistic insights into potential clinical benefit. BBA Clin. 2017 Aug;8: 66-77.

16 Murphy AJ, Woollard KJ, Hoang A, Mukhamedova N, Stirzaker RA, McCormick SP, et al. High-density lipoprotein reduces the human monocyte inflammatory response. Arterioscler Thromb Vasc Biol. 2008 Nov;28(11): 2071-7.

17 Mineo C, Deguchi H, Griffin JH, Shaul PW. Endothelial and antithrombotic actions of HDL. Circ Res. 2006 Jun 9;98(11):1352-64.

18 Besler C, Heinrich K, Rohrer L, Doerries C, Riwanto M, Shih DM, et al. Mechanisms underlying adverse effects of HDL on eNOS-activating pathways in patients with coronary artery disease. J Clin Invest. 2011 Jul;121(7) 2693-708.

19 Miljkovic M, Stefanovic A, Vekic J, Zeljkovic A, Gojkovic T, Simic-Ogrizovic S, et al. Activity of paraoxonase 1 (PON1) on HDL2 and HDL3 subclasses in renal disease. Clin Biochem. 2018 Sep;60:52-8.

20 Vaziri ND. HDL abnormalities in nephrotic syndrome and chronic kidney disease. Nat Rev Nephrol. 2016 Jan;12(1):37-47.

21 Honda H, Ueda M, Kojima S, Mashiba S, Michihata T, Takahashi K, et al. Oxidized high-density lipoprotein as a risk factor for cardiovascular events in prevalent hemodialysis patients. Atherosclerosis. 2012 Feb; 220(2):493-501.

22 Florens N, Calzada C, Lemoine S, Boulet MM Guillot N, Barba C, et al. CKD increases carbonylation of HDL and is associated with impaired antiaggregant properties. J Am Soc Nephrol. 2020 Jul;31(7):1462-77.

23 Mikolasevic I, Žutelija M, Mavrinac V, Orlic L. Dyslipidemia in patients with chronic kidney disease: etiology and management. Int J Nephrol Renovasc Dis. 2017;10:35-45.

24 Lamprea-Montealegre JA, Staplin N, Herrington WG, Haynes R, Emberson J, Baigent C, et al. Apolipoprotein B, triglyceride-rich lipoproteins, and risk of cardiovascular events in persons with CKD. Clin J Am Soc Nephrol. 2020 Jan 7;15(1):47-60.

25 Konishi H, Miyauchi K, Tsuboi S, Ogita M, Naito R, Dohi T, et al. Plasma lipoprotein(a) predicts major cardiovascular events in patients with chronic kidney disease who undergo percutaneous coronary intervention. Int $J$ Cardiol. 2016 Feb;205(205):50-3.

26 Bajaj A, Damrauer SM, Anderson AH, Xie D, Budoff MJ, Go AS, et al. Lipoprotein(a) and risk of myocardial infarction and death in chronic kidney disease: findings from the CRIC Study (Chronic Renal Insufficiency Cohort). Arterioscler Thromb Vasc Biol. 2017 Oct;37(10):1971-8.
27 Tsimikas S. A test in context: lipoprotein(a): diagnosis, prognosis, controversies, and emerging therapies. J Am Coll Cardiol. 2017 Feb 14;69(6):692-711.

28 Hopewell JC, Haynes R, Baigent C. The role of lipoprotein (a) in chronic kidney disease. J Lipid Res. 2018 Apr;59(4):577-85.

29 Bermudez-Lopez M, Forne C, Amigo N, Bozic M, Arroyo D, Bretones T, et al. An indepth analysis shows a hidden atherogenic lipoprotein profile in non-diabetic chronic kidney disease patients. Expert Opin Ther Targets. 2019Jul;23(7):619-30.

30 Tsimikas S, Gordts PLSM, Nora C, Yeang C, Witztum JL. Statin therapy increases lipoprotein(a) levels. Eur Heart J. 2020 Jun 21; 41(24):2275-84.

31 Ren Z, Fan Y, Li A, Shen Q, Wu J, Ren L, et al. Alterations of the human gut microbiome in chronic kidney disease. Adv Sci. 2020 Sep; 7(20):2001936.

32 Thomas C, Gioiello A, Noriega L, Strehle A, Oury J, Rizzo G, et al. TGR5-mediated bile acid sensing controls glucose homeostasis. Cell Metab. 2009 Sep;10(3):167-77.

33 He J, Zhang P, Shen L, Niu L, Tan Y, Chen L, et al. Short-chain fatty acids and their association with signalling pathways in inflammation, glucose and lipid metabolism. Int J Mol Sci. 2020 Sep 2;21(17).

34 Warrier M, Shih DM, Burrows AC, Ferguson D, Gromovsky AD, Brown AL, et al. The TMAO-generating enzyme flavin monooxygenase 3 is a central regulator of cholesterol balance. Cell Rep. 2015 Jan 20;10(3):32638.

35 Shih DM, Wang Z, Lee R, Meng Y, Che N, Charugundla S, et al. Flavin containing monooxygenase 3 exerts broad effects on glucose and lipid metabolism and atherosclerosis. J Lipid Res. 2015 Jan;56(1):22-37.

36 Canyelles $M$, Tondo $M$, Cedó L, Farràs M, Escolà-Gil JC, Blanco-Vaca F. Trimethylamine $\mathrm{N}$-oxide: a link among diet, gut microbiota, gene regulation of liver and intestine cholesterol homeostasis and HDL function. Int $J$ Mol Sci. 2018 Oct 19;19(10).

37 Mekki K, Bouzidi-bekada N, Kaddous A, Bouchenak M. Mediterranean diet improves dyslipidemia and biomarkers in chronic renal failure patients. Food Funct. 2010 Oct;1(1): 110-5.

38 Beddhu S, Abraham J. Risk factor paradox in CKD and ESRD: does a healthy lifestyle matter? Clin J Am Soc Nephrol. 2013 Apr;8(4): 515-7.

39 Fontes BC, Anjos JSD, Black AP, Moreira NX, Mafra D. Effects of low-protein diet on lipid and anthropometric profiles of patients with chronic kidney disease on conservative management. J Bras Nefrol. 2018 Jul-Sep;40(3): 225-32.

40 Salmean YA, Zello GA, Dahl WJ. Foods with added fiber improve stool frequency in individuals with chronic kidney disease with no impact on appetite or overall quality of life. BMC Res Notes. 2013 Dec 5;6:510.
41 Zhao YH, Fan YJ. Resveratrol improves lipid metabolism in diabetic nephropathy rats. Front Biosci. 2020 Jun 1;25:1913-24.

42 Grundy SM, Stone NJ, Bailey AL, Beam C, Birtcher KK, Blumenthal RS, et al. 2018 AHA/ ACC/AACVPR/AAPA/ABC/ACPM/ADA/ AGS/APhA/ASPC/NLA/PCNA guideline on the management of blood cholesterol: executive summary: a report of the American College of Cardiology/American Heart Association Task Force on Clinical Practice Guidelines. Circulation. 2019 Jun 18;139(25): e1046-81.

43 Mach F, Baigent C, Catapano AL, Koskinas KC, Casula M, Badimon L, et al. 2019 ESC/ EAS Guidelines for the management of dyslipidaemias: lipid modification to reduce cardiovascular risk. Eur Heart J. 2020 Jan 1;41(1): $111-88$.

44 Anderson TJ, Grégoire J, Pearson GJ, Barry AR, Couture P, Dawes M, et al. 2016 Canadian cardiovascular society guidelines for the management of dyslipidemia for the prevention of cardiovascular disease in the adult. Can J Cardiol. 2016 Nov;32(11):1263-82.

45 Shepherd J, Kastelein JJ, Bittner V, Deedwania P, Breazna A, Dobson S, et al. Intensive lipid lowering with atorvastatin in patients with coronary heart disease and chronic kidney disease: the TNT (Treating to New Targets) study. J Am Coll Cardiol. 2008 Apr 15; 51(15):1448-54.

46 Koren MJ, Davidson MH, Wilson DJ, Fayyad RS, Zuckerman A, Reed DP, et al. Focused atorvastatin therapy in managed-care patients with coronary heart disease and CKD. Am J Kidney Dis. 2009 May;53(5):741-50.

47 Herrera-Gomez F, Chimeno MM, MartinGarcia D, Lizaraso-Soto F, Maurtua-BrisenoMeiggs A, Grande-Villoria J, et al. Cholesterol-lowering treatment in chronic kidney disease: multistage pairwise and network meta-analyses. Sci Rep. 2019 Jun 20;9(1): 8951.

48 Hou W, Lv J, Perkovic V, Yang L, Zhao N, Jardine MJ, et al. Effect of statin therapy on cardiovascular and renal outcomes in patients with chronic kidney disease: a systematic review and meta-analysis. Eur Heart J. 2013 Jun; 34(24):1807-17.

49 Lin YC, Lai TS, Wu HY, Chou YH, Chiang WC, Lin SL, et al. Effects and safety of Statin and Ezetimibe combination therapy in patients with chronic kidney disease: a systematic review and meta-analysis. Clin Pharmacol Ther. 2020 Oct;108(4):833-43.

$50 \mathrm{Su}$ X, Zhang L, Lv J, Wang J, Hou W, Xie X, et al. Effect of statins on kidney disease outcomes: a systematic review and meta-analysis. Am J Kidney Dis. 2016 Jun;67(6):881-92.

51 Ecder T. Statins in the treatment of autosomal dominant polycystic kidney disease. Nephrol Dial Transplant. 2016 Aug;31(8):1194-6.

52 Wong MG, Wanner C, Knight J, Perkovic V. Lowering cholesterol in chronic kidney disease: is it safe and effective? Eur Heart J. 2015 Nov 14;36(43):2988-95. 36 
53 Marz W, Genser B, Drechsler C, Krane V, Grammer TB, Ritz E, et al. Atorvastatin and low-density lipoprotein cholesterol in type 2 diabetes mellitus patients on hemodialysis. Clin J Am Soc Nephrol. 2011 Jun;6(6):131625.

54 Streja E, Gosmanova EO, Molnar MZ, Soohoo M, Moradi H, Potukuchi PK, et al. Association of continuation of statin therapy initiated before transition to chronic dialysis therapy with mortality after dialysis initiation. JAMA Netw Open. 2018 Oct 5;1(6):e182311.

55 Harris KP, Wheeler DC, Chong CC. Atorvastatin in CSICapd. A placebo-controlled trial examining atorvastatin in dyslipidemic patients undergoing CAPD. Kidney Int. 2002 Apr;61(4):1469-74.

56 Baigent C, Landray MJ, Reith C, Emberson J, Wheeler DC, Tomson C, et al. The effects of lowering LDL cholesterol with simvastatin plus ezetimibe in patients with chronic kidney disease (Study of Heart and Renal Protection): a randomised placebo-controlled trial. Lancet. 2011 Jun 25;377(9784):2181-92.

57 Goldfarb-Rumyantzev AS, Habib AN, Baird BC, Barenbaum LL, Cheung AK. The association of lipid-modifying medications with mortality in patients on long-term peritoneal dialysis. Am J Kidney Dis. 2007 Nov;50(5): 791-802.

58 Jun M, Zhu B, Tonelli M, Jardine MJ, Patel A, Neal B, et al. Effects of fibrates in kidney disease: a systematic review and meta-analysis. J Am Coll Cardiol. 2012 Nov 13;60(20):206171.

59 Yen CL, Fan PC, Lin MS, Lee CC, Tu KH, Chen CY, et al. Fenofibrate delays the need for dialysis and reduces cardiovascular risk among patients with advanced CKD. J Clin Endocrinol Metab. 2021 May 13;106(6): 1594-605.

60 Yaribeygi H, Mohammadi MT, Rezaee R, Sahebkar A. Fenofibrate improves renal function by amelioration of NOX-4, IL-18, and p53 expression in an experimental model of diabetic nephropathy. J Cell Biochem. 2018 Sep;119(9):7458-69.

61 Yokote K, Yamashita S, Arai H, Araki E, Suganami $\mathrm{H}$, Ishibashi $\mathrm{S}$, et al. Long-term efficacy and safety of pemafibrate, a novel selective peroxisome proliferator-activated receptor-alpha modulator (SPPARMalpha), in dyslipidemic patients with renal impairment. Int J Mol Sci. 2019 Feb 6(3):20.

62 Lin MH, Yang HY, Yen CL, Wu CY, Jenq CC, Kuo G, et al. Pioglitazone is associated with lower major adverse cardiovascular and cerebrovascular events than DPP4-inhibitors in diabetic patients with end-stage renal disease: a Taiwan Nationwide Cohort Study, 20062016. J Clin Med. 2020 Nov;6(11):9.

63 Yen CL, Wu CY, See LC, Li YJ, Tseng MH, Peng WS, et al. Pioglitazone reduces mortality and adverse events in patients with type 2 diabetes and with advanced chronic kidney disease: National Cohort Study. Diabetes Care. 2020 Oct;43(10):e152-3.
64 Charytan DM, Sabatine MS, Pedersen TR, Im K, Park JG, Pineda AL, et al. Efficacy and safety of evolocumab in chronic kidney disease in the FOURIER trial. J Am Coll Cardiol. 2019 Jun 18;73(23):2961-70.

65 Lee E, Gibbs JP, Emery MG, Block G, Wasserman SM, Hamilton L, et al. Influence of renal function on evolocumab exposure, pharmacodynamics, and safety. Clin Pharmacol Drug Dev. 2019 Apr;8(3):281-9.

66 Tuñón J, Steg PG, Bhatt DL, Bittner VA, Diaz $\mathrm{R}$, Goodman SG, et al. Effect of alirocumab on major adverse cardiovascular events according to renal function in patients with a recent acute coronary syndrome: prespecified analysis from the ODYSSEY OUTCOMES randomized clinical trial. Eur Heart J. 2020Nov 7; 41(42):4114-23.

67 Wright RS, Collins MG, Stoekenbroek RM, Robson R, Wijngaard PLJ, Landmesser U, et al. Effects of renal impairment on the pharmacokinetics, efficacy, and safety of inclisiran: an analysis of the ORION-7 and ORION-1 Studies. Mayo Clin Proc. 2020 Jan; 95(1):77-89.

68 Tsimikas S, Karwatowska-Prokopczuk E, Gouni-Berthold I, Tardif JC, Baum SJ, Steinhagen-Thiessen E, et al. Lipoprotein(a) reduction in persons with cardiovascular disease. N Engl J Med. 2020 Jan 16;382(3):24455.

69 Han J, Zhang R, Muheyati D, Lv MX, Aikebaier W, Peng BX. The effect of chickpea deietary fiber on lipid metabolism and gut microbiota in high-fat diet-induced hyperlipidemia in rats. J Med Food. 2021;24(2): 124-34.

70 Wang J, Li P, Liu S, Zhang B, Hu Y, Ma H, et al. Green tea leaf powder prevents dyslipidemia in high-fat diet-fed mice by modulating gut microbiota. Food Nutr Res. 2020;64.

71 Zhang W, Miikeda A, Zuckerman J, Jia X, Charugundla S, Zhou Z, et al. Inhibition of microbiota-dependent TMAO production attenuates chronic kidney disease in mice. Sci Rep. 2021 Jan 12;11(1):518.

72 Hennuyer N, Duplan I, Paquet C, Vanhoutte J, Woitrain E, Touche V, et al. The novel selective PPARalpha modulator (SPPARMalpha) pemafibrate improves dyslipidemia, enhances reverse cholesterol transport and decreases inflammation and atherosclerosis. Atherosclerosis. 2016 Jun;249:200-8.

73 Sasaki Y, Raza-Iqbal S, Tanaka T, Murakami K, Anai M, Osawa T, et al. Gene Expression profiles induced by a novel selective peroxisome proliferator-activated receptor alpha modulator (SPPARMalpha) pemafibrate. Int J Mol Sci. 2019 Nov;13(22):20.

74 Maki T, Maeda Y, Sonoda N, Makimura H, Kimura S, Maeno S, et al. Renoprotective effect of a novel selective PPARalpha modulator K-877 in db/db mice: A role of diacylglycerolprotein kinase $\mathrm{C}-\mathrm{NAD}(\mathrm{P}) \mathrm{H}$ oxidase pathway. Metabolism. 2017 Jun;71:33-45.

75 Nemeth A, Mozes MM, Calvier L, Hansmann G, Kokeny G. The PPARgamma agonist pio- glitazone prevents TGF-beta induced renal fibrosis by repressing EGR-1 and STAT3. BMC Nephrol. 2019 Jul 5;20(1):245.

76 O'Connell TD, Mason RP, Budoff MJ, Navar AM, Shearer GC. Mechanistic insights into cardiovascular protection for omega-3 fatty acids and their bioactive lipid metabolites. Eur Heart J Suppl. 2020 Oct;22(Suppl J):J320.

77 Bhatt DL, Steg PG, Miller M, Brinton EA, Jacobson TA, Ketchum SB, et al. Cardiovascular risk reduction with lcosapent ethyl for hypertriglyceridemia. N Engl J Med. 2019 Jan 3; 380(1):11-22.

78 Budoff MJ, Bhatt DL, Kinninger A, Lakshmanan S, Muhlestein JB, Le VT, et al. Effect of icosapent ethyl on progression of coronary atherosclerosis in patients with elevated triglycerides on statin therapy: final results of the EVAPORATE trial. Eur Heart J. 2020 Oct 21;41(40):3925-32.

79 Nicholls SJ, Lincoff AM, Garcia M, Bash D, Ballantyne CM, Barter PJ, et al. Effect of highdose omega-3 fatty acids vs corn oil on major adverse cardiovascular events in patients at high cardiovascular risk: the STRENGTH randomized clinical trial. JAMA. 2020 Dec 8; 324(22):2268-80.

80 Yamamoto T, Takabatake Y, Minami S, Sakai S, Fujimura R, Takahashi A, et al. Eicosapentaenoic acid attenuates renal lipotoxicity by restoring autophagic flux. Autophagy. 2020 Jun 28:1-14.

81 Wei Z, Cao J, Zhang X, Yin D, Xu D, Lu G. EPA attenuates epithelial-mesenchymal transition and fibrosis through the TGF- $\beta 1 /$ Smad3/ILK pathway in renal tubular epithelial HK-2 cells by up-regulating miR-541. Int J Clin Exp Pathol. 2019;12(7):2516-25.

82 Casula M, Olmastroni E, Boccalari MT, Tragni E, Pirillo A, Catapano AL. Cardiovascular events with PCSK9 inhibitors: an updated meta-analysis of randomised controlled trials. Pharmacol Res. 2019 May; 143:143-50.

83 Ruscica M, Greco MF, Ferri N, Corsini A. Lipoprotein(a) and PCSK9 inhibition: clinical evidence. Eur Heart J Suppl. 2020 Nov; 22(Suppl L):L53-L6.

84 Wiese GN, Biruete A, Moorthi RN, Moe SM, Lindemann SR, Hill Gallant KM. Plant-based diets, the gut microbiota, and trimethylamine $\mathrm{N}$-Oxide production in cfhronic kidney disease: therapeutic potential and methodological considerations. J Ren Nutr. 2021 Mar.

85 Agarwal A, Prasad GV. Post-transplant dyslipidemia: mechanisms, diagnosis and management. World J Transplant. 2016 Mar 24; 6(1):125-34.

86 Co MLF, Agdamag AC, Co MZ, Hertl M, Mohamedali $\mathrm{B}$. Intensity-dependent benefit of statins in survival among prospective kidney transplant patients. Am J Cardiol. 2019 Jan 15;123(2):254-9.

87 Agrawal S, Zaritsky JJ, Fornoni A, Smoyer WE. Dyslipidaemia in nephrotic syndrome: mechanisms and treatment. Nat Rev Nephrol. 2018 Jan;14(1):57-70. 